\title{
Morphological Structure of Leaves and Particulate Matter Capturing Capability of Common Broad-leaved Plant Species in Beijing
}

\author{
H.X. Wang \& Y.H. Wang \\ Institute of Forest Ecology, Environment and Protection, Chinese Academy of Forestry, Beijing 100091, \\ China
}

J. Yang, B.Z. Xie, H. Shi

School of Environmental and Municipal Engineering, Xi'an University of Architecture and Technology, Xi'an 710055, China

ABSTRACT: Particulate matter (PM), especially the small fractions (e.g., PM with diameter less than $2.5 \mu \mathrm{m}$, $\mathrm{PM}_{2.5}$ ) is a serious health problem throughout the world. Vegetation may be used as a biological filter, with its foliage accumulating PM. Thus, massive artificial plantation has been implemented in cities as one of the helpful measures to alleviate the PM pollution. PM accumulation on leaves of 13 species was examined in test field in Beijing using washing-filtering method. The results showed that leaf PM in different size fractions $\left(\mathrm{PM}_{>10}, \mathrm{PM}_{2.5-10}, \mathrm{PM}_{0.1-2.5}\right)$ and total $\mathrm{PM}$ differed significantly among the tested species. Buxus megistophylla was the most efficient species for PM accumulation per unit leaf area, while leaves of Salix babylonica accumulated least PM per unit leaf area. Important traits for PM accumulation were leaf properties such as the size of the microstructure, stomatal density, and wax shape and structure. The ranking in terms of PM accumulation can be used to select the suitable species to remove PM pollution in urban areas.

KEYWORD: Air pollution alleviation; Leaves; Particulate matter; $\mathrm{PM}_{2.5}$; Urban plants

\section{INTRODUCTION}

Particulate matter (PM) pollution is a serious threat to the health and life quality of the urban population. The adverse effects of PM on human health are associated with exposure to increased levels of PM, especially the small fractions, like $\mathrm{PM}_{2.5}$ (PM with diameter less than $2.5 \mu \mathrm{m}$ ) (Dockey \& Pope 1994; Tchepel \& Dias 2011). Thus, reducing the PM concentration in ambient air, especially $\mathrm{PM}_{2.5}$ is considered as one of the most significant tasks related to environmental protection in urban areas.

Vegetation can be used as biological filters, with its foliage accumulating PM (e.g., Liu et al. 2013; McDonald et al. 2007; Wang et al. 2013). McDonald et al. (2007) estimated that trees in West Midland and Greater London area could remove 110 and 852-2121 t of $\mathrm{PM}_{10}$ (PM with diameter less than 10 $\mu \mathrm{m})$ annually, respectively. In Guangzhou, China, the leaves of Ficus virens, Ficus microcarpa, Bauhinia blakeana, and Mangifera indica can remove 8013 tons of PM per year (Liu et al. 2013). Trees in city center of Beijing accumulated 772 tons of $\mathrm{PM}_{10}$ in a year (Yang et al. 2005). Thus, one can conclude that urban vegetation has a direct positive effect on air quality by removing PM. If trees and other vegetation were employed as part of an effort to decrease airborne PM, especially $\mathrm{PM}_{2.5}$, the difference in PM accumulation among tree species should be determined and the most efficient species should be used. However, studies comparing PM deposition among species are few, especially for $\mathrm{PM}_{25}$.

This study examined PM and its size fractions accumulation by 13 common species in Beijing. The findings of this study can provide useful information to use of trees to improve air quality and provide guidance for the work of urban planners.

\section{MATERIALS AND METHODS}

\subsection{Plant materials and experiment site}

Five individual sample trees of 13 plant species, Buxus megistophylla, Koelreuteria paniculata, Prunus cerasifera, Ligustrum quihoui, Lagerstroemia indica, Fraxinus chinensis, Acer truncatum, Ginkgo biloba, Magnolia denudate, Sophora japonica, Platanus acerifolia, Populus tomentosa, and Salix babylonica were selected for analysis at Beijing Botanical Garden (39 $\left.59^{\prime} 29.66^{\prime \prime} \mathrm{N}, 116^{\circ} 12^{\prime} 40.25^{\prime \prime} \mathrm{E}\right)$. The mean $\mathrm{PM}_{2.5}$ and $\mathrm{PM}_{10}$ concentrations from May to October, 2013 are 74.12 \pm 57.81 , and $90.31 \pm 53.39 \mu \mathrm{g} / \mathrm{m}^{3}$, respectively, as measured at the nearest monitoring station (Beijing Municipal Environmental Monitoring Center, 2013). 


\subsection{Leaf sampling}

Leaf sampling was conducted on $1^{\text {st }}$ October, 2013, at a point in time without rainfall for more than a week. All sample trees were suffering from no obvious pests or diseases. From each sample tree, 50-150 pieces of mature and healthy leaves were collected from the inner and outer canopy of N, W, $\mathrm{S}$, and $\mathrm{E}$ facing aspects at a height of 2-6 m, 0.5-3 m above ground, for trees and shrubs, respectively. Then, a bulk sample for each tree species was formed by putting all collected leaves of five sample trees into polyethylene bags.

\subsection{Analysis of PM}

For each plant species, three batches of test material were initially prepared, and enough leaves were selected. The selected leaves were immersed in 200 $\mathrm{mL}$ of ultrapure water (ELGA, Buckinghamshire, UK) and the leave surfaces were cleaned with a nohair-loss brush. The leaves were carefully removed with tweezers and rinsed with distilled water. Each solution was then passed through three types of microporous membranes with the pore size of 10 , 2.5 , and $0.1 \mu \mathrm{m}$ to collect the PM size fractions of > $10,2.5-10$ and $0.1-2.5 \mu \mathrm{m}$, respectively, and denoted as $\mathrm{PM}_{>10}, \mathrm{PM}_{2.5-10}, \mathrm{PM}_{0.1-2.5}$. Then the membrane were oven dried at $40^{\circ} \mathrm{C}$ to a constant weight. The leaf $\mathrm{PM}_{>10}, \mathrm{PM}_{2.5-10}$, and $\mathrm{PM}_{0.1-2.5}$ were calculated as

$$
W=\left(W_{2}-W_{1}\right) / A
$$

where $W$ is the leaf $\mathrm{PM}_{>10}, \mathrm{PM}_{2.5-10}$, and $\mathrm{PM}_{0.1-2.5}$ capturing capacity $\left(\mathrm{g} / \mathrm{m}^{2}\right)$, and $A$ is hemi-surface area of the leaves $\left(\mathrm{m}^{2}\right)$. The leaf area was determined with Image $\mathbf{J}$ software (Version 1.46; National Institutes of Health, Bethesda, MD, USA) after scanning (HP Scanjet 3570c, HP, Japan). The sum of $\mathrm{PM}_{>10}, \mathrm{PM}_{2.5-10}$, and $\mathrm{PM}_{0.1-2.5}$ was the total leaf PM accumulation.

\subsection{Scanning electron microscopy observation}

For every species, two pieces (about $5 \times 5 \mathrm{~mm}$ ) cut from the center of the leaves were fixed to aluminum stubs with double-sided adhesive tape. Then the samples were sputter-coated with a thin layer of gold-palladium using a precision etching coating system (Model 682, Ga-tan Co., Ltd., Pleasanton, CA, USA). Finally, the samples were examined with a field emission scanning electron microscopy (FESEM, Quanta 200 FEG; FEI Company, Hillsboro, OR, USA).

\subsection{Data analysis}

Statistical analysis was performed with Minitab 16 software (Minitab Ltd., Shanghai, China). One-way analysis of variance was applied to determine if significant differences in leaf PM and its size fractions capturing capacities among species. When analysis of variance indicated significant differences among species, Tukey's honestly significant difference multiple comparisons test was performed to determine which exhibited significant differences. A given effect was assumed significant at $p<0.05$.

\section{RESULTS AND DISCUSSION}

\subsection{Differences in PM and its size fractions accumulation among species}

The total amount of PM deposited on leaves was significantly different among species $(p<0.001$, Table 1). B. megistophylla had the greatest total accumulated PM per unit leaf area, while $S$. babylonica had the smallest per unit leaf area. The amounts of size fractions of leaf deposited PM also showed significant difference among tree species ( $p$ $<0.001$, Table 1). On all species, the $\mathrm{PM}_{>10}$ and $\mathrm{PM}_{0.1-2.5}$ made up the greatest $(66.4 \%-92.9 \%)$ and smallest $(3.7 \%-8.7 \%)$ proportion of accumulated total PM, respectively (Table 1).

Table 1. Particulate matter accumulated on unit leaf area of plant species $\left(\mathrm{g} / \mathrm{m}^{2}\right)$ and its size fraction percentage $(\%$, shown in parentheses

\begin{tabular}{|c|c|c|c|c|}
\hline Species & $\mathrm{PM}_{0.1-2.5}$ & $\mathrm{PM}_{2.5-10}$ & $\mathrm{PM}_{>10}$ & PM \\
\hline \multirow{2}{*}{$\begin{array}{c}\text { B. } \\
\text { megistophylla }\end{array}$} & $0.17 \pm 0.14$ & $0.21 \pm 0.06$ & $1.89 \pm 0.32$ & $2.27 \pm 0.14$ \\
\hline & $(7.8 \pm 6.6)$ & $(9.2 \pm 3.3)$ & $(83.0 \pm 9.7)$ & \\
\hline \multirow{2}{*}{ K. paniculata } & $0.12 \pm 0.03$ & $0.06 \pm 0.01$ & $1.34 \pm 0.56$ & $1.52 \pm 0.59$ \\
\hline & $(8.1 \pm 2.2)$ & $(4.2 \pm 0.1)$ & $(87.7 \pm 3.1)$ & \\
\hline \multirow{2}{*}{ P. cerasifera } & $0.10 \pm 0.05$ & $0.13 \pm 0.04$ & $0.93 \pm 0.10$ & $1.16 \pm 0.15$ \\
\hline & $(8.7 \pm 3.2)$ & $(11.1 \pm 3.2)$ & $(80.2 \pm 5.5)$ & \\
\hline \multirow{2}{*}{ L. quihoui } & $0.10 \pm 0.01$ & $0.11 \pm 0.03$ & $1.34 \pm 0.44$ & $1.55 \pm 0.47$ \\
\hline & $(6.7 \pm 1.8)$ & $(7.0 \pm 1.3)$ & $(86.3 \pm 2.7)$ & \\
\hline \multirow{2}{*}{ L. indica } & $0.09 \pm 0.07$ & $0.11 \pm 0.03$ & $1.10 \pm 0.36$ & $1.30 \pm 0.42$ \\
\hline & $(6.8 \pm 2.9)$ & $(9.1 \pm 3.4)$ & $(84.1 \pm 4.7)$ & \\
\hline \multirow{2}{*}{ F. chinensis } & $0.07 \pm 0.02$ & $0.11 \pm 0.03$ & $0.93 \pm 0.23$ & $1.11 \pm 0.27$ \\
\hline & $(6.3 \pm 0.7)$ & $(10.0 \pm 0.9)$ & $(83.7 \pm 2.2)$ & \\
\hline \multirow{2}{*}{ A. truncatum } & $0.06 \pm 0.02$ & $0.07 \pm 0.06$ & \begin{tabular}{|l|}
$1.62 \pm 0.41$ \\
\end{tabular} & $1.75 \pm 0.47$ \\
\hline & $(3.7 \pm 0.4)$ & $(3.4 \pm 1.4)$ & $(92.9 \pm 1.2)$ & \\
\hline \multirow{2}{*}{ G. biloba } & $0.06 \pm 0.02$ & $0.09 \pm 0.01$ & $0.83 \pm 0.03$ & $0.98 \pm 0.02$ \\
\hline & $(6.5 \pm 2.4)$ & $(8.8 \pm 1.3)$ & $(84.7 \pm 1.5)$ & \\
\hline \multirow{2}{*}{ M. denudata } & $0.06 \pm 0.03$ & $0.09 \pm 0.01$ & $1.24 \pm 0.23$ & $1.39 \pm 0.25$ \\
\hline & $(4.1 \pm 2.5)$ & $(6.4 \pm 1.1)$ & $(89.5 \pm 1.9)$ & \\
\hline \multirow{2}{*}{ S. japonica } & $0.05 \pm 0.03$ & $0.05 \pm 0.01$ & $0.53 \pm 0.08$ & $0.63 \pm 0.07$ \\
\hline & $(7.8 \pm 4.9)$ & $(7.4 \pm 1.6)$ & $(84.8 \pm 5.3)$ & \\
\hline \multirow{2}{*}{ P. acerifolia } & $0.04 \pm 0.01$ & $0.31 \pm 0.16$ & $1.09 \pm 0.32$ & $1.44 \pm 0.20$ \\
\hline & $(8.6 \pm 1.5)$ & $(25.0 \pm 6.9)$ & $(66.4 \pm 8.2)$ & \\
\hline \multirow{2}{*}{ P. tomentosa } & $0.04 \pm 0.01$ & $0.06 \pm 0.01$ & $0.80 \pm 0.12$ & $0.90 \pm 0.13$ \\
\hline & $(4.4 \pm 0.3)$ & $(6.4 \pm 0.5)$ & $(89.2 \pm 1.7)$ & \\
\hline \multirow{2}{*}{ S. babylonica } & $0.04 \pm 0.01$ & $0.07 \pm 0.03$ & $0.50 \pm 0.12$ & $0.61 \pm 0.12$ \\
\hline & $(5.2 \pm 2.7)$ & $(12.5 \pm 5.3)$ & $(82.3 \pm 14.5)$ & \\
\hline
\end{tabular}


Previous studies have shown that leaf PM retention amounts showed variances among species. Sæbø et al. (2012) found that the PM accumulation of the 47 plant species showed significantly difference among species. Pinus mugo, Pinus sylvestris, Taxus media, Taxus baccata, Stephanandra incise, and Betula pendula were the efficient species, while Acer platanoides, Prunus avium, and Tilia cordata were the less efficient species. The species considered here documented the differences in PM retention amount among species that provides additional evidence for the variation of leaf PM retention. This information suggest that if urban vegetation is to be employed as a measure to decrease PM in the air, then the most efficient species should be used.

Here, we also found that leaf accumulated PM was dominated by large particles, and the fine particles made up the smallest proportion of the accumulated PM. The leaves of $P$. acerifolia accumulated $90 \%$ of PM with diameter larger than $10 \mu \mathrm{m}$, while only $5.5 \%$ of PM with diameter less than $3 \mu \mathrm{m}$ (Hofman et al. 2014). Terzaghi et al. (2013) found that $87-95 \%, 5-12 \%$, and $0.1-0.5 \%$ of the particles deposited on leaves of Cornus mas, Acer pseudoplatanus, and Pinus pinea were $\mathrm{PM}_{>10}$,
$\mathrm{PM}_{2.5-10}$, and $\mathrm{PM}_{2.5}$, respectively. The higher proportion of fine particles observed here maybe due to the difference in plant species, air particle concentration and composition.

\subsection{Leaf surface micromorphology of some typical plant species and its relation with PM capturing ability}

In the FESEM study, epicuticular wax was observed in tubular form (Figs 1D, E) or it could be in the form of wax membrane (Figs 1A-C, F). The epidermal cells on the adaxial surface of $B$. megistophylla (Fig. 1A), F. chinensis (Fig. 1C) and G. biloba (Fig. 1D) were convex. For P. cerasifera (Fig. 1B), there were many ridges and hollows on the adaxial surface. However, the adaxial surface of $S$. japonica (Fig. 1E) and P. tomentosa (Fig. 1F) were relatively smooth. The stomatal apparatus only distributed on the abaxial surface and were sunken into epidermis (Figs 1B, D-F) except $B$. megistophylla (Fig. 1A) and F. chinensis (Fig. 1C). The stomata on the FESEM images with a magnification of 1000 was $24,34,8,6,5$, and 12 for B. megistophylla, P. cerasifera, $F$. chinensis, $G$. biloba, S. japonica, and $P$. tomentosa, respectively.
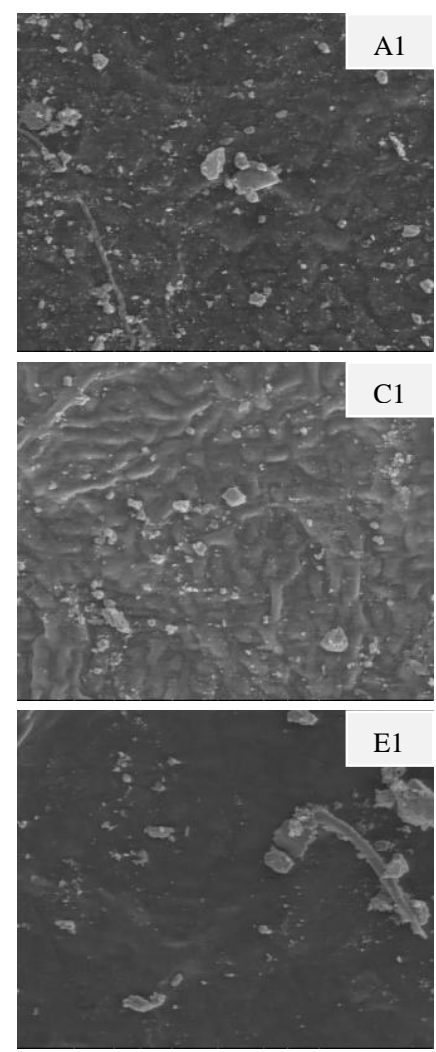
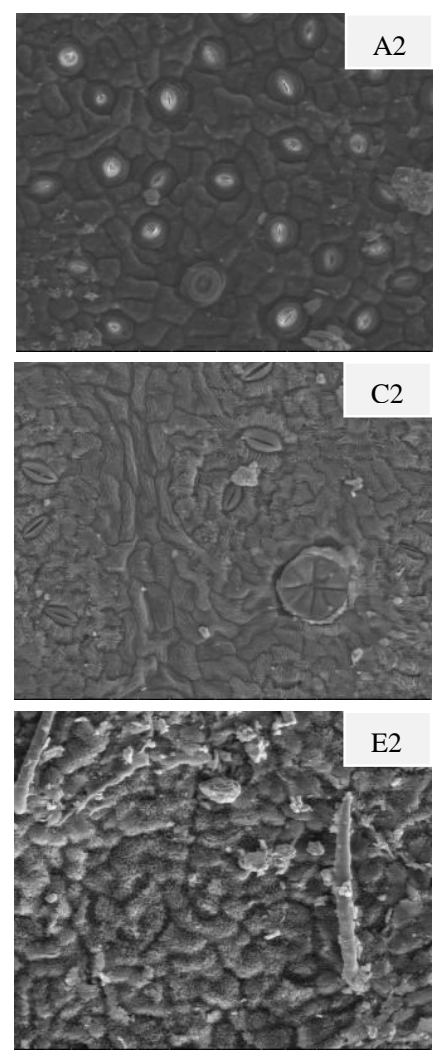
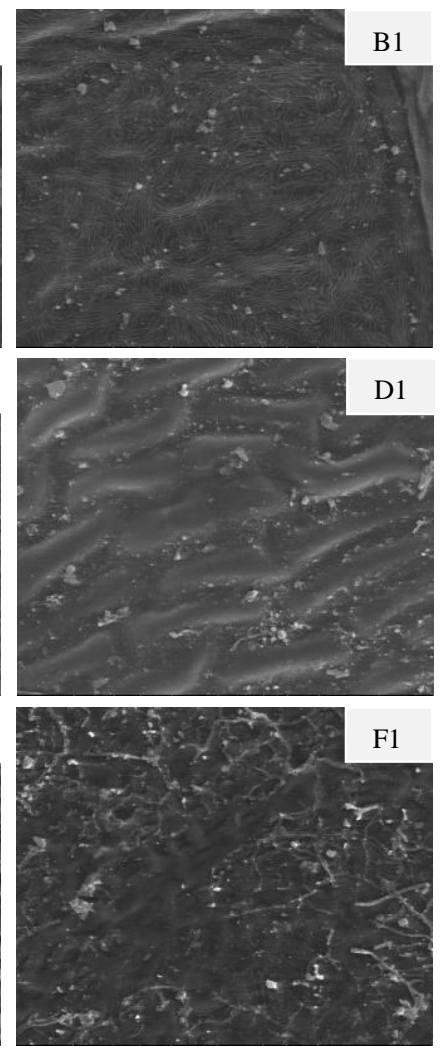
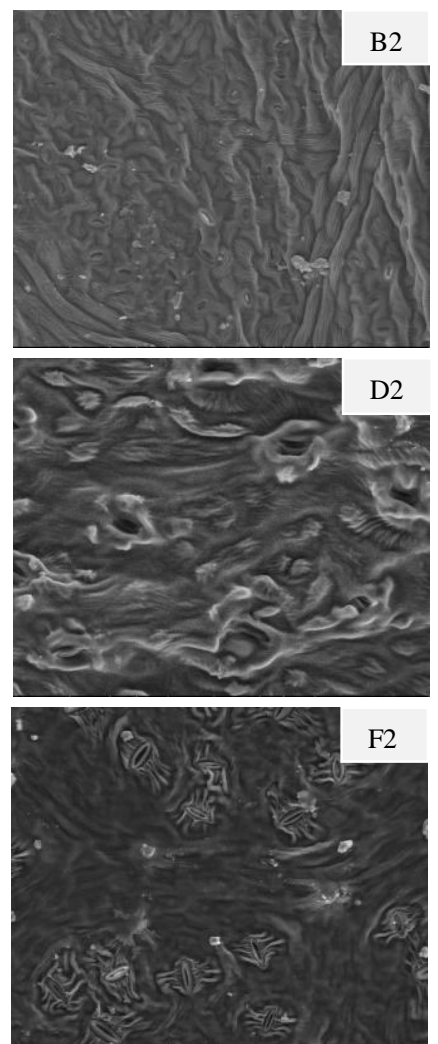

Figure 1. Scanning electron micrographs (× 1000) of Buxus megistophylla (A), Prunus cerasifera (B), Fraxinus chinensis (C), Ginkgo biloba (D), Sophora japonica (E), and Populus tomentosa (F). 1: adaxial surface, 2: abaxial surface.

Particles mainly deposited on the adaxial surfaces except $S$. japonica (Fig. 1E), only very few deposited in the stomatal regions on abaxial surfaces. In addition, the smaller PM fractions mainly deposited in or around the hollow of the leaf surfaces.
Plant species may display different PM accumulation capacities depending on leaf morphological structures (e.g., leaf stomatal density, the shape and amount of trichomes), leaf area, as well as the prevailing meteorological conditions (Liu 
et al. 2013; Räsänen et al. 2013; Sæbø et al. 2012; Wang et al. 2013). For instance, research has shown that leaves with low stomatal density, high stomatal conductance, and higher amounts of leaf hairiness more frequently capture $\mathrm{NaCl}$ particles (Räsänen et al. 2013). Leaves with wax crystals were less efficient than the species with wax films (Wang et al. 2013). This was true when $G$. biloba and $S$. japonica were compared with other species. In this study, we found that fine particles mainly deposited in or around the hollow structures of the leaf surfaces, suggesting that the size of the morphological structure determined the quantity of fine particles accumulation. In the present study, we found the increase of stomatal density would increase the amounts of PM captured, especially the fine fraction. A large stomatal density may result in increased transpiration; this can make particles more deliquescent and can increase deposition rates (Burkhardt et al. 2001) because of the hygroscopicity of the fine particles (Burkhardt 2010). Thus, we could conclude that the species with ridges and large stomatal density might have higher PM accumulation abilities.

\section{CONCLUSION}

(i) Leaf accumulated PM differed significantly among the 13 plant species, B. megistophylla had the greatest total accumulated PM per unit leaf area, while $S$. babylonica had the smallest per unit leaf area.

(ii) The PM with diameter large than $10 \mu \mathrm{m}$ dominated the amount of leaf accumulated PM, while the proportion of fine particles was the smallest.

(iii) Leaf morphological structure affects the PM accumulation, the leaves with ridges and hollows, higher stomatal density had higher PM accumulation abilities.

\section{ACKNOWLEDGEMENTS}

This work was supported by the Forestry Public Project of China (No. 201304301-05). We thank Professor Wenyan YANG and Research Assistant Rong WANG of the State Key Laboratory of Tribology, TsingHua University, for assistance with the field emission scanning electron microscopy. We sincerely thank Gaobing CHEN and Dong LI, Henan University of Science and Technology, for collecting leaf samples in the field.

\section{REFERENCES}

[1] Beijing Municipal Environmental Monitoring Center. 2013. Ambient air quality daily report (2013-05-01-201310-31). http://www.bjmemc.com.cn/ (in Chinese)

[2] Burkhardt, J. 2010. Hygroscopic particles on leaves: nutrients or desiccants? Ecological Monograph 80: 369399.

[3] Burkhardt, J., Koch, K., Kaiser, H. 2001. Deliquescence of deposited atmospheric particles on leaf surfaces. Water, Air, \& Soil Pollution 1(5-6): 313-321.

[4] Dockery, D.W. \& Pope III, C.A. 1994. Acute respiratory effects of particulate air pollution. Annual Review of Public Health 15(1): 107-132.

[5] Hofman, J., Wuyts, K., Van Wittenberghe, S., Brackx, M., Samson, R. 2014. On the link between biomagnetic monitoring and leaf-deposited dust load of urban trees: relationships and spatial variability of different particle size fractions. Environmental Pollution 189: 63-72.

[6] Liu, L., Guan, D.S., Peart, M.R., Wang, G., Zhang, H., Li, Z.W. 2013. The dust retention capacities of urban vegetation-a case study of Guangzhou, South China. Environmental Science and Pollution Research 20: 66016610.

[7] McDonald, A.G., Bealey, W.J., Fowler, D., Dragosits, U., Skiba, U., Smith, R.I., Donovan, R.G., Brett, H.E., Hewitt, C.N., Nemitz, E. 2007. Quantifying the effect of urban tree planting on concentrations and depositions of PM10 in two UK conurbation. Atmospheric Environment 41: 84558467.

[8] Räsänen, J.V., Holopainen, T., Joutsensaari, J., Ndam, C., Pasanen, P., Rinnan, Å., Kivimäenpää, M. 2013. Effects of species-specific leaf characteristics and reduced water availability on fine particle capture efficiency of trees. Environmental Pollution 183: 64-70.

[9] Sæbø, A., Popek, R., Nawrot, B., Hanslin, H.M., Gawronska, H., Gawronski, S.W. 2012. Plant species differences in particulate matter accumulation on leaf surfaces. Science of the Total Environment 427-428: 347354.

[10] Tchepel, O. \& Dias, D. 2011. Quantification of health benefits related with reduction of atmospheric PM10 levels: implementation of population mobility approach. International Journal of Environmental Health Research 21(3): 189-200.

[11] Terzaghi, E., Wild, E., Zacchello, G., Cerabolini, B.E.L., Jones, K.C., Guardo, A.D. 2013. Forest Filter Effect: Role of leaves in capturing/releasing air particulate matter and its associated PAHs. Atmospheric Environment 74: 378384.

[12] Wang, H.X., Shi, H., Li, Y.Y., Yu, Y., Zhang, J. 2013. Seasonal variations in leaf capturing of particulate matter, surface wettability and micromorphology in urban tree species. Frontiers of Environmental Science and Engineering 7(4): 579-588.

[13] Yang, J., McBride, J., Zhou, J.X., Sun, Z.Y. 2005. The urban forest in Beijing and its role in air pollution reduction. Urban Forestry \& Urban Greening 3: 65-78. 